\title{
Proposal for the establishment of a manufacturing cell: a case study in a metallurgical company
}

Patrícia Stefan de Carvalho ${ }^{1}$,Universidade Federal de Santa Maria

Vanessa Andréia Schneider ${ }^{2}$,Universidade Federal de Santa Maria

Leandro Parreira ${ }^{3}$, Faculdades Integradas Machado de Assis

Alexandre Chapoval Neto ${ }^{4}$, Universidade Regional Integrada do Alto Uruguai e das Missões

\section{RESUMO}

Este estudo remete à importância da gestão da produção, onde conhecer os processos em profundidade é uma questão imprescindível para a redução de desperdícios. O trabalho foi motivado através da seguinte problemática: De que maneira a implantação de uma célula de manufatura com layout celular pode contribuir para aumentar a produtividade? No qual o objetivo foi propor a implantação de uma célula de manufatura que atenda às necessidades de aumento produtivo e eliminação de desperdícios. O mapeamento de fluxo de valor foi utilizado no entendimento do processo atual e simulação do processo futuro, a ferramenta gráfica Yamazumi foi usada na análise da distribuição das operações, e o diagrama de espaguete na comparação do layout atual com o proposto. Através da implantação de uma célula de manufatura, projeta-se redução do tempo de produção em 8 dias, com ganho potencial no tempo de produção de $27,58 \%$, possibilitando produzir 3 peças a mais por dia, além da melhora do giro de estoque de $37,63 \%$ e redução de 3 pessoas envolvidas com a fabricação. O presente estudo apresentou a diminuição dos desperdícios em $20 \%$, e otimização das atividades que agregam valor durante a cadeia produtiva.

Palavras-chave: Célula de manufatura. Mapeamento de fluxo de valor. Redução de desperdícios. Yamazumi.

\section{ABSTRACT}

This study refers to the importance of production management, where knowing the processes in depth is an essential feature for the reduction of waste. The work was motivated by the following problem: How can the establishment of a manufacturing cell with a cellular layout help to increase productivity? The objective of the study was to propose the implantation of a manufacturing cell that meets the needs of productive increase and elimination of waste. The value stream mapping was used to understand the current process and simulation of the future process, while the Yamazumi graphical tool was used in the analysis of the distribution of operations, and the spaghetti diagram was used to compare the current layout with the proposed one. Through the establishment of a manufacturing cell, a reduction in production time of 8 days was projected, with a potential gain in production time of $27.58 \%$, making it possible to produce 3 more pieces a day, in addition to an improvement in the inventory turnover of $37.63 \%$ and a reduction of 3 people involved in manufacturing. The present study showed a decrease in waste of $20 \%$, and optimization of the activities that add value throughout the productive chain.

Keywords: Manufacturing cell. Value Stream Mapping. Reduction of waste. Yamazumi.

1. Av. Roraima no 1000, INPE - Prédio 08, Sala 2057, Bairro Camobi, Santa Maria - RS, CEP: 97105-900, patricia_stefanc@hotmail.com; 2. vanessaandreias@gmail.com; 3. leandro.parreira@nelsongp.com.br; 4. chapoval_alex@yahoo.com.br CARVALHO, P. S.; SCHNEIDER, V. A.; PARREIRA, L.; CHAPOVAL NETO, A. Proposta de implantação de uma célula de manufatura: um estudo de caso em uma metalúrgica. GEPROS. Gestão da Produção, Operações e Sistemas, v. 14, n. 4, p. 114 - 133, 2019.

DOI: $10.15675 /$ gepros.v14i4.2302
Editor Responsável: Prof. Dr. Hermes Moretti Ribeiro da Silva 
Proposta de implantação de uma célula de manufatura: um estudo de caso em uma metalúrgica

\section{INTRODUÇÃO}

O atual comportamento mercadológico mostra-se crescentemente competitivo, onde as organizações que se destacam aliam produtividade, redução de custos e eliminação de desperdícios, focando em qualidade e entrega no prazo. Com isso, torna-se evidente a importância da criação de mecanismos que atuem elevando a eficiência produtiva, aumentando seu faturamento e incentivando investimentos na estrutura funcional da organização (SANTOS, et al., 2016).

Para tanto, é essencial definir a melhor maneira de gestão, conhecendo os processos como um todo e aplicando metodologias de trabalho bem definidas, como a adequação ao layout celular. Células de manufatura são agrupamentos de máquinas, que visam a melhoria nos processos produtivos (MANTINS, LAUGENI, 2012)

O sistema Lean, busca minimizar os desperdícios existentes na organização, levando a um fluxo contínuo, minimizando o lead time do processo e elevando o nível de qualidade através da melhoria contínua tanto dos processos, como dos seus produtos (BARTZ, WEISE, RUPPENTHAL, 2013). Womack e Jones (2004) definem desperdício como qualquer atividade humana que absorve recursos, mas não cria valor, como por exemplo erros que exigem retificação, acúmulo de mercadorias nos estoques e movimentação de funcionários.

Muitos estudos abordam o tema eliminação de desperdícios e sistema Lean. Nawanir, Lim e Othman (2016), desenvolveram um trabalho no qual pesquisaram o nível de implementação do Lean Manufacturing entre as empresas de manufatura na Indonésia, em termos de recursos flexíveis, layouts celulares, produção de lotes pequenos, nível de produção uniforme, qualidade, troca rápida de ferramentas e rede de fornecedores. No trabalho realizado por Bartz, Weise e Ruppenthal (2013), devido ao alto lead time, desenvolveu-se o mapeamento de processos, identificando as atividades que não agregavam valor ao produto, apresentando ações de melhoria.

No estudo feito por Pinheiro e Toledo (2016), são discutidas informações a respeito da implantação de conceitos Lean no processo de desenvolvimento de produtos em empresas. Leite et al. (2017) realizaram um trabalho no qual teve o objetivo de apresentar uma proposta de melhoria de processo a partir da ferramenta mapa de fluxo de valor em uma empresa de manufatura. 
Proposta de implantação de uma célula de manufatura: um estudo de caso em uma metalúrgica

A célula de manufatura se mostra muitas vezes uma opção viável à muitas organizações. Gadelha et al. (2015) investigaram quais os benefícios da utilização de um layout de manufatura celular em uma indústria de transformadores. Outro estudo, elaborado por Rosa et al. (2014), teve como objetivo analisar o atual arranjo físico de uma empresa fabricante de cilindros hidráulicos, buscando o planejamento das melhorias de layout para contribuir com a maximização do rendimento dos fatores produtivos. Ao final de ambos os trabalhos, obteve-se uma série de benefícios.

Objetivando a busca pela melhoria contínua, existem diversos métodos para analisar os processos produtivos, observando se estes estão corretamente alinhados ou não, e dessa forma, rastrear os problemas, encontrando a melhor maneira de solucioná-los. Dentre as metodologias de trabalho voltadas ao gerenciamento de processos que mais se destacam, estão a adequação do layout celular e ferramentas como o mapeamento de fluxo de valor, ambas utilizadas neste estudo de caso.

O que instigou a presente pesquisa foi a seguinte problemática: De que maneira a implantação de uma célula de manufatura com layout celular para terminais de mangueira de ar condicionado pode contribuir para aumentar a produtividade desses itens? Pois o alto lead time da empresa laboratório do estudo provocou atrasos na fabricação dos itens estudados após a inserção dos mesmos na produção, uma vez que antes estes eram terceirizados, e devido à problemas com o fornecedor, optou-se pela fabricação interna.

Para solucionar o problema, o objetivo do estudo foi propor a implantação de uma célula de manufatura que atenda às necessidades de aumento produtivo e eliminação de desperdícios. Dessa forma, através de um estudo de caso foi feito um levantamento do processo atual da organização, comparando-o com a simulação do processo futuro considerando uma célula de manufatura. Para atender ao objetivo, foi escolhido um item de maior relevância e elaborou-se o diagrama de espaguete, mapeamento de fluxo de valor e Yamazumi, apresentando ao final do estudo uma série de melhorias para a empresa.

\section{REFERENCIAL TEÓRICO}

\subsection{Desperdícios}

A preocupação por parte dos gestores e colaboradores das empresas em relação aos desperdícios decorrentes dos processos deve sempre ser colocada em pauta, uma vez que segundo Koenigsaecker (2011), o sistema Lean lista os sete desperdícios, sendo eles: GEPROS. Gestão da Produção, Operações e Sistemas, v. 14, nº 4, p. 114 - 133, 2019. 
Proposta de implantação de uma célula de manufatura: um estudo de caso em uma metalúrgica

superprodução, fabricar com defeitos, transportes, estoque, superprocessamento, tempo de espera e movimentação desnecessária.

A maioria dos desperdícios listados pelo Sistema Toyota de Produção são minimizados com a otimização do layout produtivo, principalmente no que diz respeito aos desperdícios de transporte, de estoque e de movimentação (SHINGO, 1996).

\subsection{Célula de Manufatura}

O layout celular mostra-se uma opção válida para muitas empresas, levando-se em consideração suas atividades e ramo de atuação (TRINTIN, SELLITTO, 2013). Quanto a organização das máquinas em uma célula de manufatura, deve-se utilizar equipamentos pequenos dedicados a tarefas simples, organizando as peças o mais próximo possível do local de uso para que o operador possa utilizar ambas as mãos (ROTHER, HARRIS, 2008).

A principal característica de uma célula de manufatura é a flexibilidade quanto ao tamanho de lotes por produto, o que permite alto nível de qualidade e produtividade, diminui também o transporte de material e os estoques, e ainda envolve satisfação no trabalho (MARTINS, LAUGENI, 2012). No arranjo celular as peças movem-se uma por vez, sendo projetada para ser flexível, normalmente é arranjada em forma de "U", de tal forma que os operadores posam mover-se de máquina para máquina, carregando ou descarregando peças (BLACK, 1998).

\subsection{Mapeamento de processos}

Quanto ao mapeamento de processos, Rother e Shook (2012), relatam que deve-se usar uma caixa de processo, indicando um processo pelo qual o material está fluindo, que deve ser desenhado da esquerda para a direita, na parte de baixo do mapa. Os autores descrevem ainda que abaixo de cada caixa de processo, deve-se ter uma caixa de dados, contendo informações referentes aos processos como: o tempo de ciclo (T/C), tempo de troca (TR), número de pessoas, o tempo de trabalho disponível por turno, e o tempo de operação.

Martins e Laugeni (2012), dizem que os tempos padrões de produção poderão ser usados como uma referência futura, para avaliar o desempenho de uma determinada célula de produção, para tanto, realiza-se uma cronometragem para obter os dados necessários, determinando o tempo médio. Mapear o fluxo de valor consiste em observar diretamente o fluxo das informações e dos materiais/serviços no estado atual, focando no resultado futuro GEPROS. Gestão da Produção, Operações e Sistemas, v. 14, n 4, p. 114 - 133, 2019. 
Proposta de implantação de uma célula de manufatura: um estudo de caso em uma metalúrgica

(WOMACK, JONES, 2011). Contudo, os autores relatam que esta não é uma tarefa fácil para as organizações, pois a mesma deve dispor de profissionais habilitados por se tratar de uma atividade estratégica de busca por melhores resultados.

Um estudo realizado por Prates e Bandeira (2011), consistiu no aumento da eficiência por meio do mapeamento de fluxo de valor, onde, através da medição dos tempos de ciclos com a ajuda de um cronômetro, pode-se observar que existiam muitos pontos falhos durante o processo, como excesso nas etapas de retrabalho e inspeção $(84,5 \%)$, enquanto que as operações que agregam valor era mínimas $(15,5 \%)$

\subsection{Yamazumi}

Foi utilizado no trabalho a ferramenta gráfica Yamazumi, que de acordo com Pieńkowski (2014), é uma ferramenta que pode ser usada para visualizar os desperdícios, servindo para realçar a carga de trabalho dentro ou entre processos.

Yamazumi é um quadro onde está descrito a distribuição de trabalho entre os operadores, baseado em dados reais que foram coletados e registrados. É quantitativo, simples, visual e retira as estimativas e aproximações no projeto e operação eficientes de células baseadas em operadores (ROTHER, HARRIS, 2008).

\section{PROCEDIMENTOS METODOLÓGICOS}

\subsection{Objeto de estudo}

Quanto à abordagem utilizada no trabalho, fez-se o uso do método qualitativo e quantitativo. A abordagem qualitativa se faz presente na busca pela compreensão do problema em questão, analisando o processo produtivo atual da empresa, bem como a proposta de implantação de uma célula de manufatura. O método quantitativo, por sua vez, foi utilizado na análise dos dados numéricos, como a série histórica dos terminais, na mensuração dos tempos da produção atual e simulação da proposta.

Já em relação aos procedimentos, foram utilizados os métodos de pesquisa descritiva, comparativa e estudo de caso. A pesquisa descritiva se deu através do registro e descrição dos fatos. A pesquisa comparativa foi usada na comparação de ambos os processos produtivos, além da comparação entre tempos e movimentos de um processo com o outro e a comparação dos ganhos e benefícios. 
Proposta de implantação de uma célula de manufatura: um estudo de caso em uma metalúrgica

O estudo de caso, de acordo com Yin (2001), é uma pesquisa que examina em profundidade um fenômeno contemporâneo, nesse caso, se deu na compreensão do problema, de forma que se tenha o melhor custo benefício, enfocando no conhecimento sobre assuntos como célula de manufatura, layout, demanda, tempos e movimentos, com o intuito de contribuir com a empresa em questão.

A empresa laboratório para este estudo, fabrica uma diversificada linha de produtos, entre eles a linha de itens estruturais e itens hidráulicos, sendo que este último compreende mangueiras hidráulicas e mangueiras de ar condicionado. Atualmente a empresa é a maior fabricante independente de conjuntos de tubos. Os produtos finalizados são absorvidos por indústrias multinacionais do ramo de máquinas agrícolas.

Os itens selecionados para serem analisados neste estudo de caso, são terminais de mangueira de ar condicionado, um componente que anteriormente era terceirizado, e desta forma não interferia na produção interna da empresa, pois os mesmos chegavam ao recebimento, onde realizava-se a inspeção de qualidade e o destino ao almoxarifado. $\mathrm{O}$ armazenamento dava-se até surgir a necessidade de fabricação.

Optou-se por realizar o estudo referente à otimização da fabricação interna destes produtos, em virtude de problemas enfrentados com o fornecimento dos mesmos e sua inserção na linha de produção sem um estudo prévio, o que impactou na produção interna da empresa, devido à grande quantidade de produtos inseridos com os demais itens produzidos.

\subsection{Procedimentos de coleta de dados}

Para as técnicas de coleta de dados, foi utilizada a técnica da observação, entrevista e pesquisa documental. Foram observados os processos produtivos da empresa pertinentes ao estudo, para obter um melhor entendimento, com o fim de compreender os mesmos. A técnica da entrevista se deu através das conversas informais com colaboradores da empresa com o fim de levantar dados.

Essa pesquisa foi realizada através de documentos da empresa, como a série histórica da produção dos itens, tempos de produção e tipos de máquinas utilizadas. Para a coleta dos tempos, foi usada a técnica da cronometragem na obtenção do tempo médio. Isto se deu através do uso de um cronômetro e do acompanhamento de uma ordem de produção na fábrica por um colaborador da empresa. Os dados históricos dos itens, como a quantidade produzida e tempo de operação, foram obtidos através do sistema ERP da empresa. Esse GEPROS. Gestão da Produção, Operações e Sistemas, v. 14, nº 4, p. 114 - 133, 2019. 
Proposta de implantação de uma célula de manufatura: um estudo de caso em uma metalúrgica

sistema era alimentado por um colaborador que realizava a cronoanálise com o auxílio de um cronômetro, fazendo o uso de planilhas eletrônicas (Excel) para o cálculo das médias. O intervalo de confiança utilizado nas medidas dos tempos foi de $95 \%$.

Quanto às técnicas de análise de dados usadas no trabalho, foi a ferramenta Excel e o software SolidWorks na elaboração do layout dos processos atuais da empresa, bem como para o layout da proposta de célula de manufatura, e também para o desenho da peça em estudo.

\subsection{Procedimentos de análise de dados}

Os itens em estudo podem ser visualizados na Figura 1 e são itens hidráulicos, sendo terminais que são prensados nas mangueiras de ar condicionado para máquinas agrícolas, como tratores e colheitadeiras.

Figura 1 - Exemplo de terminais de mangueira de ar acondicionado.

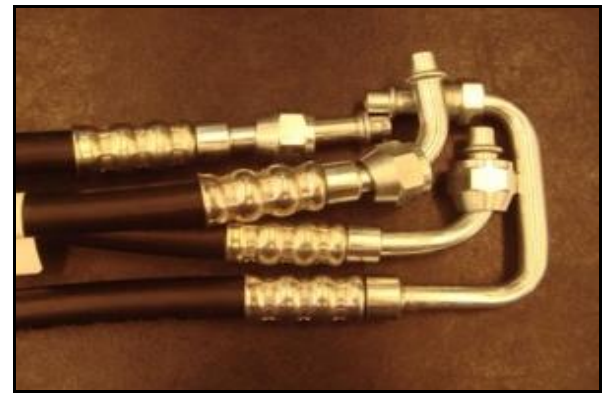

Fonte: Os autores (2018).

A alta demanda pelos terminais em estudo, bem como a inserção destes na cadeia produtiva da empresa, acarretou em atraso na produção, visto que ao realizar um comparativo da produção do primeiro semestre de 2015 com o primeiro semestre de 2016, notou-se o significativo aumento de 2029\%, resultado este referente apenas aos terminais, desconsiderando a procura dos clientes por novos produtos e a fabricação dos itens de linha.

Utilizou-se a ferramenta do gráfico de Pareto para determinar os itens de maior saída. Conforme Peinado e Graeml (2007), o diagrama de Pareto serve para demonstrar a importância relativa das variáveis de um problema, indicando quanto cada uma destas variáveis representa, em termos percentuais, do problema geral. 
Proposta de implantação de uma célula de manufatura: um estudo de caso em uma metalúrgica

Após utilização do gráfico de Pareto, foram selecionados 12 terminais de maior importância e realizada uma análise referente ao tempo total de produção (lead time), verificando o tempo esperado e o tempo real necessário para a fabricação completa dos itens, podendo ser visualizado na Figura 2, onde o tempo está representado em dias.

Figura 2 - Lead time dos terminais com o tempo em dias.

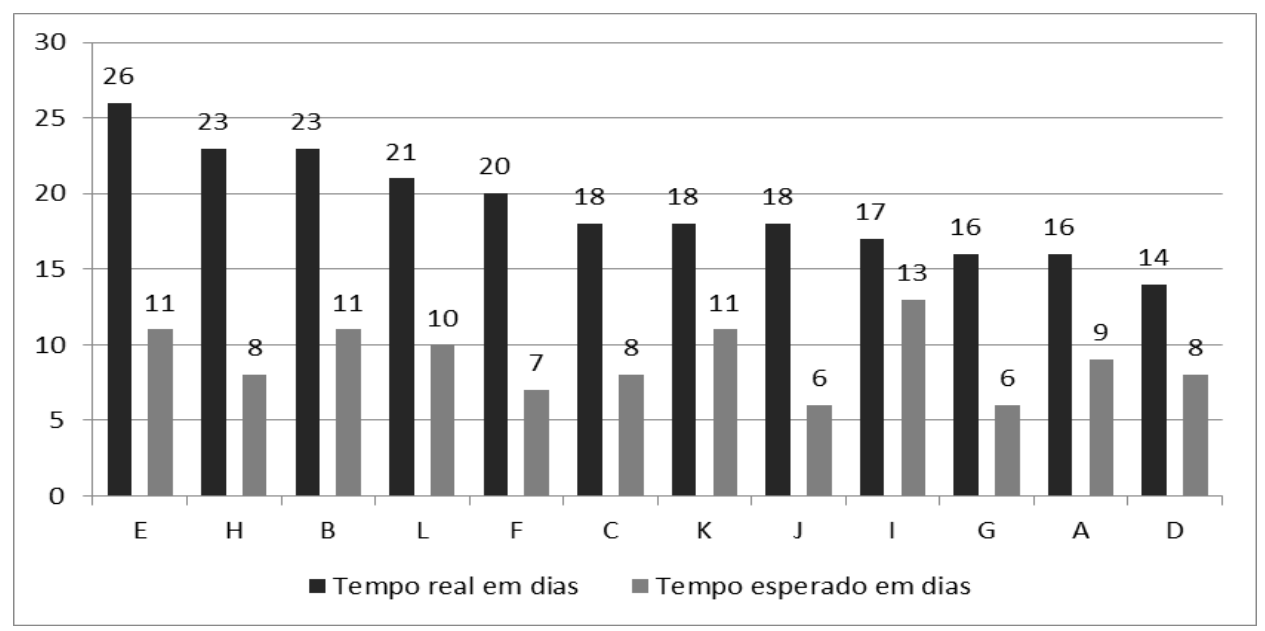

Fonte: Os autores (2018).

A partir da Figura 2 é possível analisar a diferença entre o tempo de produção esperado e o tempo real, resultando em um atraso significativo da produção. Quanto ao item E, por exemplo, a previsão para sua produção é de 11 dias e este estava sendo produzido em 26 dias. $\mathrm{O}$ estudo foi direcionado usando como referência o terminal $\mathrm{K}$, por ser um dos itens que possui o maior número de processos.

Para a representação do layout foi usada a ferramenta do diagrama de espaguete. Elaborou-se o mapa de fluxo de valor do estado atual, gerando uma ordem de produção do item $\mathrm{K}$ com a quantidade de 10 peças e acompanhada na fábrica, cronometrando todos os tempos de processo e movimentação com um cronômetro digital. Elaborou-se o Yamazumi dos processos, com o fim de identificar as atividades que agregam valor e os desperdícios.

\section{RESULTADOS}

Para realizar o mapa de fluxo de valor, primeiramente faz-se necessário o conhecimento dos processos pertinentes à fabricação do terminal $\mathrm{K}$, disponíveis no Quadro 1 . Além disso, foi feita a análise de todos os tempos, como tempo de processo, setup, lead time, 
Proposta de implantação de uma célula de manufatura: um estudo de caso em uma metalúrgica

bem como os movimentos e número de pessoas necessárias para a fabricação de um determinado produto em cada processo.

Quadro 1 - Etapas de fabricação do terminal K.

\begin{tabular}{|c|c|}
\hline PROCESSO & DESCRIÇÃO \\
\hline Corte e escareação & $\begin{array}{l}\text { Consiste no corte da matéria prima (tubos hidráulicos) de acordo com o tipo de } \\
\text { material, o diâmetro e espessura, que constam na ordem de produção. }\end{array}$ \\
\hline Flange & Realiza-se uma espécie de 'amassamento' em um local do tubo. \\
\hline Dobra & $\begin{array}{l}\text { Dobra-se a peça de acordo com o raio médio, disponível no desenho e na ordem } \\
\text { de produção. }\end{array}$ \\
\hline Recorte & $\begin{array}{l}\text { Utilizado quando a parte reta de uma ou das duas extremidades do tubo for menor } \\
\text { do que a ferramenta de dobra suporta. }\end{array}$ \\
\hline Solda brasagem por indução & $\begin{array}{l}\text { Consiste na união de componentes metálicos através de um material que une esses } \\
\text { componentes através da sua fusão, nesse caso, é soldado uma espiga em uma das } \\
\text { extremidades do tubo do terminal. }\end{array}$ \\
\hline Furação & $\begin{array}{l}\text { Processo responsável por realizar um furo na peça utilizando uma broca de acordo } \\
\text { com o diâmetro do componente a ser soldado posteriormente em cima desse furo. }\end{array}$ \\
\hline $\begin{array}{l}\text { Solda brasagem por } \\
\text { oxigênio }\end{array}$ & $\begin{array}{l}\text { A solda é realizada a partir da queima de gases, e nesse caso é utilizada para } \\
\text { soldar uma válvula em cima do furo. }\end{array}$ \\
\hline Zincagem & $\begin{array}{l}\text { É depositada sobre a superfície das peças uma camada de zinco, cuja finalidade é } \\
\text { a de proteger contra a oxidação. Processo terceirizado, pois o processo de } \\
\text { zincagem da empresa é por imersão. }\end{array}$ \\
\hline
\end{tabular}

Fonte: Os autores (2018).

A Figura 3 consiste no terminal $\mathrm{K}$ com os processos finalizados.

Figura 3 - Terminal $\mathrm{K}$ finalizado.

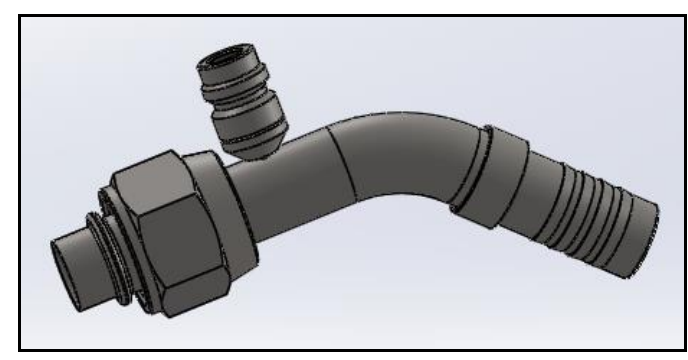

Fonte: Os autores (2018).

O layout atual da empresa consiste no layout por processo, pois assim como diz a literatura, este está organizado de modo que as máquinas com a mesma função são agrupadas 
Proposta de implantação de uma célula de manufatura: um estudo de caso em uma metalúrgica

em departamentos, sendo um meio de produção flexível. Porém, conforme Conceição (2005), induz o sistema de produção a ter elevados níveis de estoque de produtos em processo, elevados níveis de movimentação de materiais, além de dificultar as tarefas de controle da produção.

O diagrama de espaguete do layout atual pode ser visualizado na Figura 4, no qual acompanhado o percurso, enumerou-se o tempo total usado com movimentação, 324 segundos, e a distância, 162 metros, ou 3,24 km por mês.

Figura 4 - Diagrama de espaguete do layout atual.

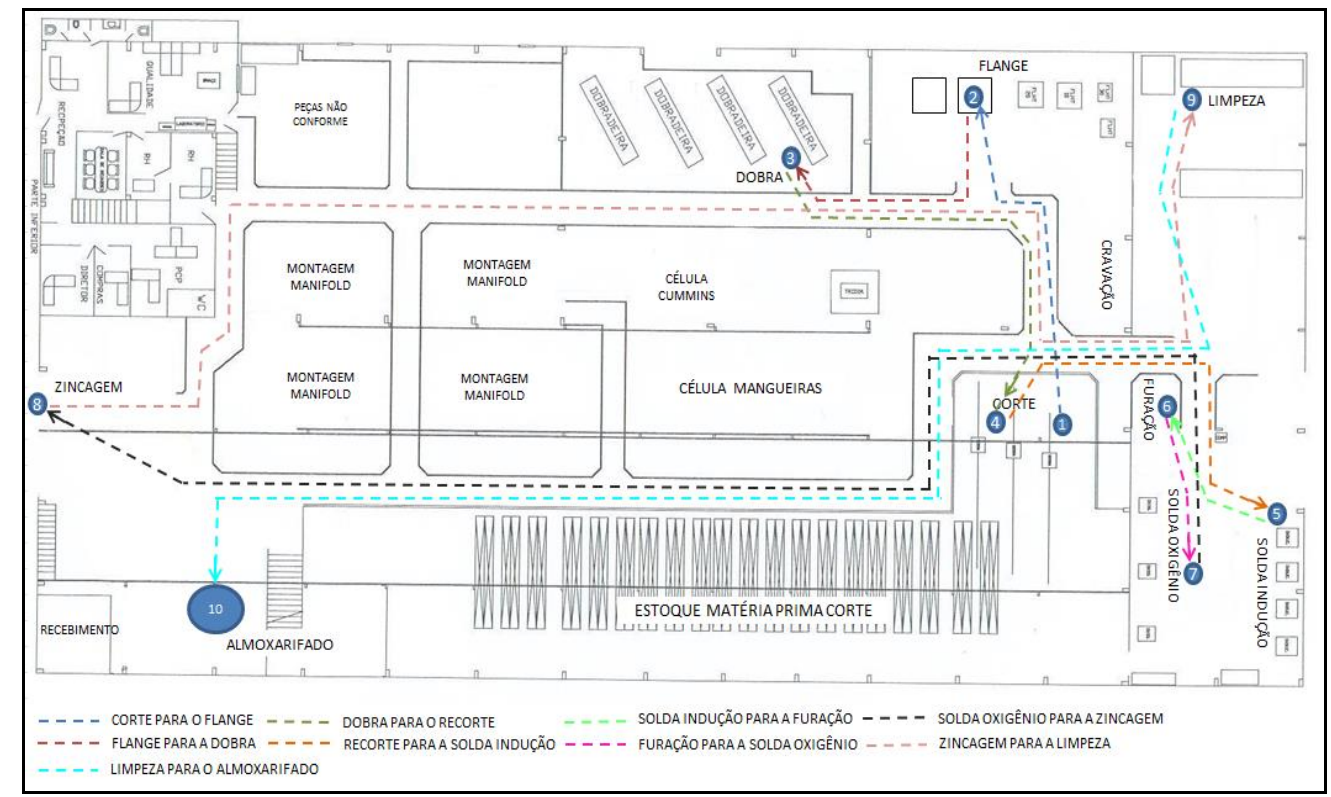

Fonte: Os autores (2018).

Posterior à isso, elaborou-se o mapa de fluxo de valor, contendo os tempos de processo e movimentação, visualizado na Figura 5. 
Proposta de implantação de uma célula de manufatura: um estudo de caso em uma metalúrgica

Figura 5 - Mapa de fluxo de valor do estado atual.

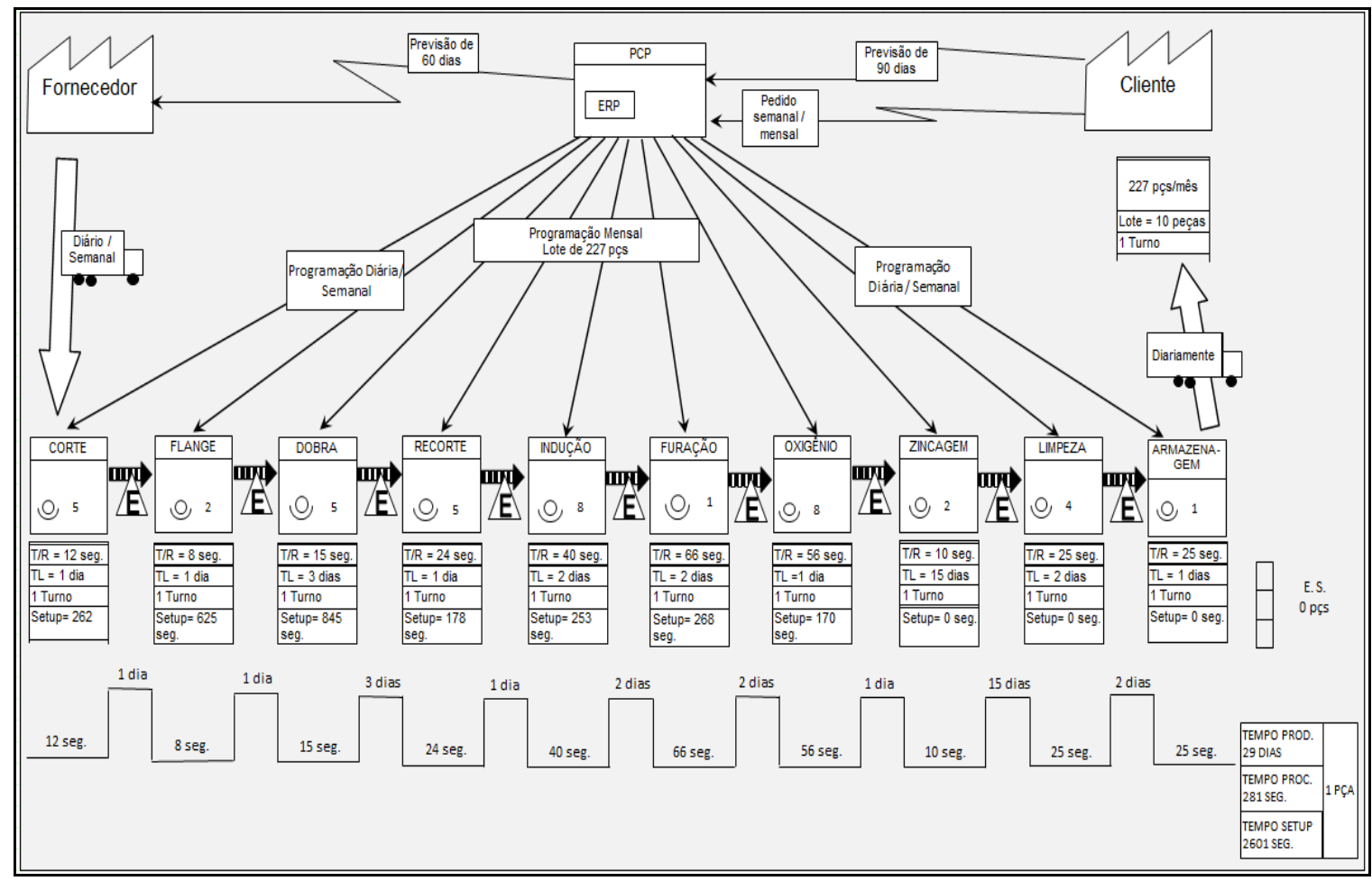

Fonte: Os autores (2018).

A furação é o processo mais demorado, com 66 segundos, e o maior tempo de setup é a dobra, com 845 segundos. Para a fabricação de uma peça, são necessários 29 dias de produção, com tempo de processamento de 281 segundos, totalizando 2601 segundos de setup. O processo que demanda mais pessoas dedicadas é a solda (dos tipos brasagem e indução), precisando de 8 pessoas. Em seguida o corte, a dobra e o recorte, cada um requerendo 5 pessoas.

Posterior à isso, tabelou-se as operações para a fabricação do terminal $\mathrm{K}$ na ferramenta do Yamazumi, o mesmo foi feito com o tempo de cada operação de acordo com seu respectivo processo. Foi gerado um gráfico para cada processo, onde são classificadas as atividades de cada um em porcentagem, distribuídas em agregação de valor (cor verde), desperdícios (cor vermelha) e atividades necessárias ao processo, mas que não agregam valor (cor laranja), de acordo com suas respectivas cores. 
Proposta de implantação de uma célula de manufatura: um estudo de caso em uma metalúrgica

A Figura 6 consiste no gráfico dos processos, sendo possível analisar graficamente os processos, de modo que o processo de recorte possui a maior taxa de desperdícios, a saber $36 \%$ das operações.

Figura 6 - Yamazumi dos processos atuais.

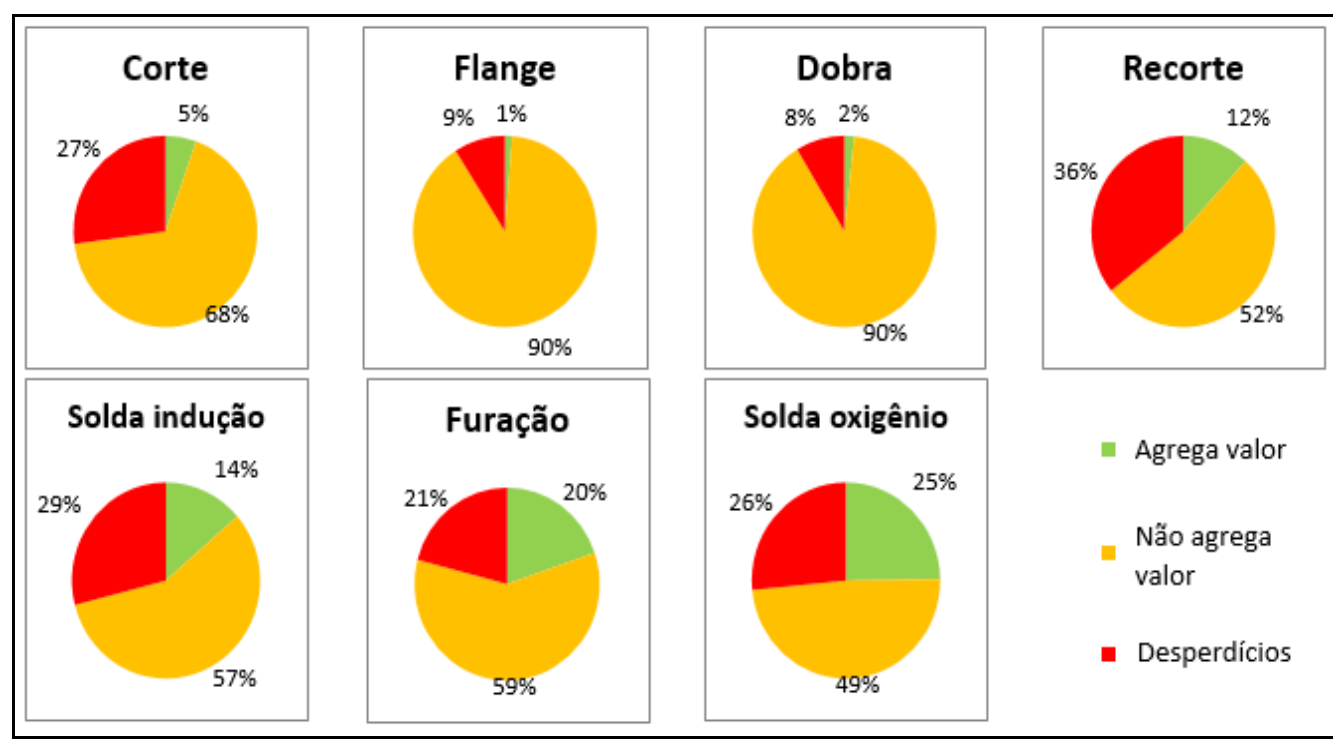

Fonte: Os autores (2018).

No processo atual, os processos estão dispostos na ordem de produção separadamente um do outro, alocados conforme a sequência das operações. Cada processo possui o seu código de barras localizado à direita da ordem de produção. Ao finalizar uma operação, o colaborador realiza o fechamento do código de barras. A produção total do terminal $\mathrm{K}$ é constituída por 10 processos e, consequentemente, são 10 códigos de barras que devem ser fechados quando finalizados os processos. Isto facilita no controle e rastreio do produto, sendo possível identificar o processo em que a peça se encontra, bem como o tempo que os operadores necessitaram para a fabricação do lote.

Os processos de flange, dobra, recorte, solda por indução, furação e solda por oxigênio, equivalem a 6 códigos de barras para realizar o fechamento da ordem de produção, demandando um total de 294 segundos para realizar o fechamento dos códigos de barra.

\subsection{Proposta de implantação da célula}

Com a finalidade de agilizar o processo atual, apresenta-se como proposta de estudo a implantação da célula de manufatura. Para tanto, seria acrescentado na produção uma 
Proposta de implantação de uma célula de manufatura: um estudo de caso em uma metalúrgica

máquina de flange, uma de recorte, uma de furação, uma de solda indução e uma de solda oxigênio, além das já existentes na fábrica, com exceção da máquina de dobra, e dispostas de acordo com os preceitos de um layout celular.

Para a elaboração do layout futuro, assim como no atual, foi usada a ferramenta do diagrama de espaguete, e para tanto, foi simulado o fluxo de movimentação para a fabricação do terminal K, dispondo os processos 2, 3, 4, 5, 6 e 7 seguindo a sequência da Figura 7, pelo fato de a maior parte dos itens adotarem esse seguimento.

Figura 7 - Diagrama de espaguete do layout proposto.

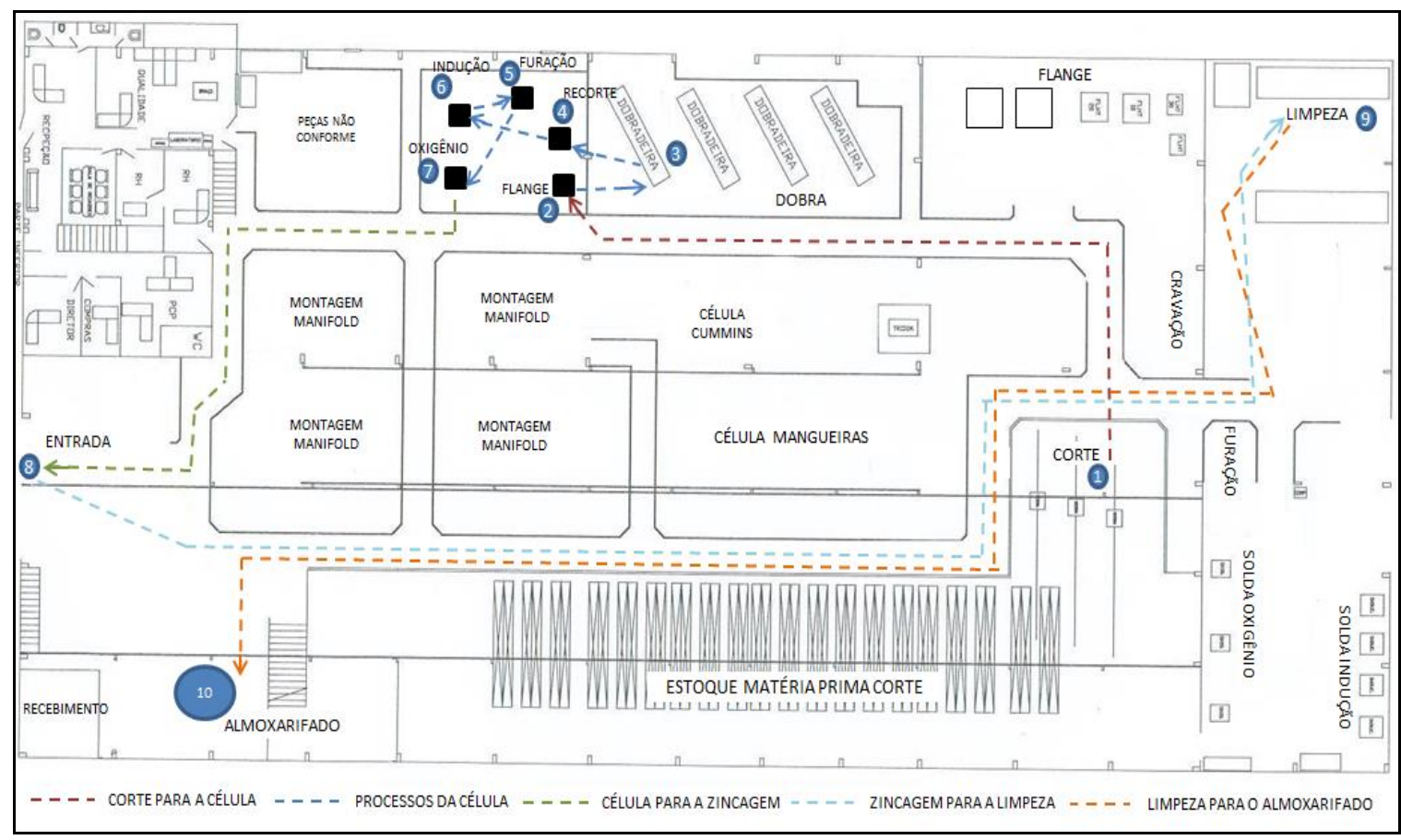

Fonte: Os autores (2018).

Conforme o estudo, os processos 2 (flange), 4 (recorte), 5 (furação), 6 (solda indução) e 7 (solda oxigênio) consistem nos processos agrupados para formar a célula de terminais. Quanto ao processo 3 (dobra), este permaneceria no local atual, por estar localizado ao lado da célula de manufatura, e dessa forma possibilitar a utilização da máquina mais próxima.

Com o layout proposto, seriam percorridos 89 metros e, considerando a produção do lote de um terminal por dia, seriam percorridos $1,78 \mathrm{~km}$ por mês. $\mathrm{Na}$ célula, as máquinas necessárias ficariam arranjadas em um só local, onde o material se deslocaria entre as mesmas, diminuindo o transporte de material, bem como os estoques entre processos. 
Proposta de implantação de uma célula de manufatura: um estudo de caso em uma metalúrgica

\subsection{Mapa de fluxo de valor futuro}

Depois de definido o layout futuro, foi elaborado o mapa de fluxo de valor conforme a Figura 8, simulando o processo futuro com a célula de manufatura instalada.

Figura 81 - Mapa de fluxo de valor do estado futuro.

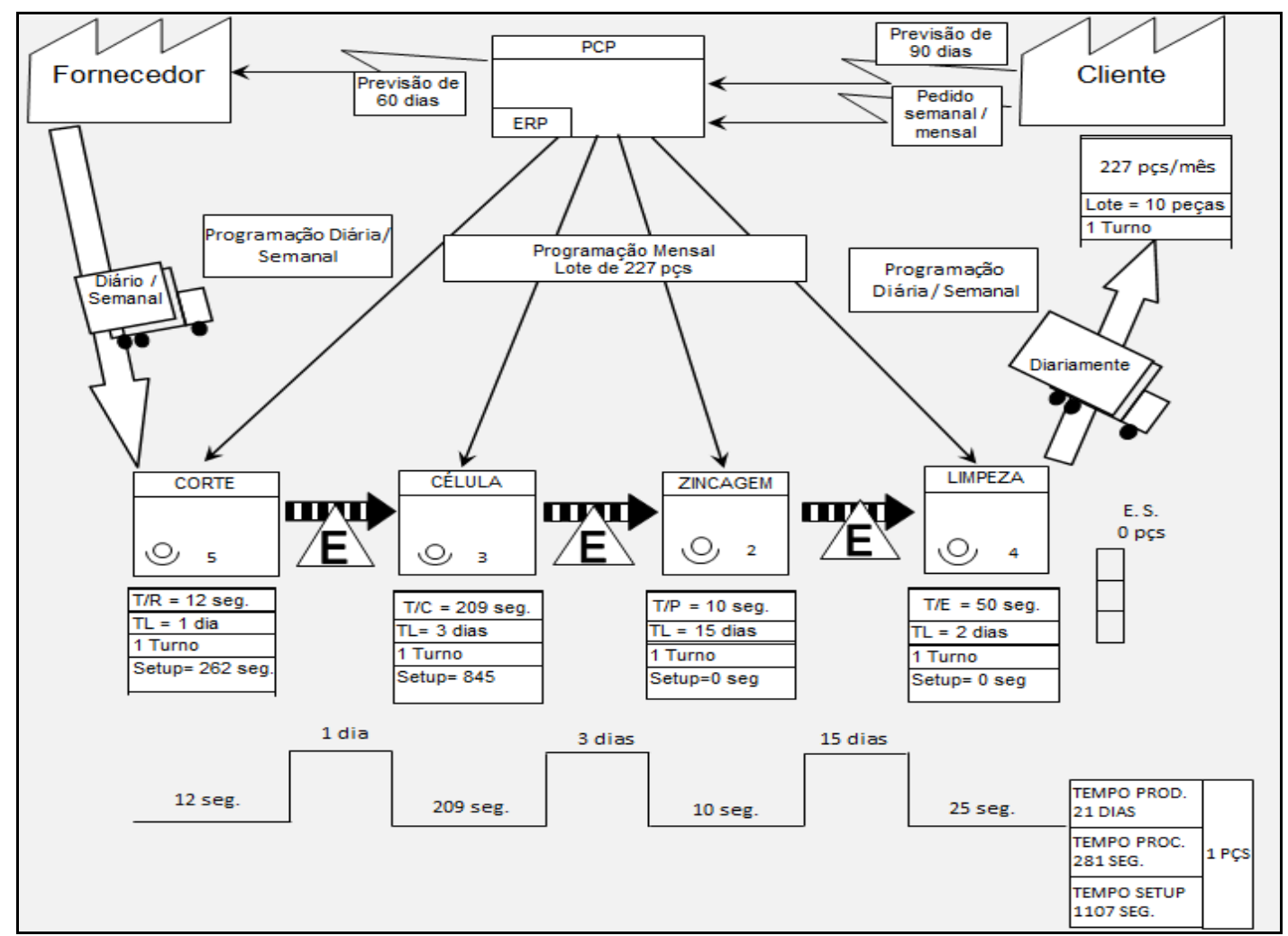

Fonte: Os autores (2018).

Sendo assim, através do mapa de fluxo de valor futuro pode-se verificar que para a produção completa de um item $\mathrm{K}$ são necessários 21 dias de produção, com tempo de processamento de 281 segundos, com tempo de setup total de 1107 segundos.

Após realizar-se e analisar a situação do mapa de fluxo de valor, elaborou-se o Yamazumi do processo futuro, classificando as atividades de acordo com agregação de valor, desperdício e operações necessárias à produção, mas que não agregam valor ao processo.

A Figura 9 consiste no Yamazumi do processo futuro ou proposto, onde os dados do processo de corte permanecem os mesmos, pois este não sofreu alteração. Já na célula de manufatura, $19 \%$ das atividades consistem em agregação de valor e $77 \%$ em atividades 
Proposta de implantação de uma célula de manufatura: um estudo de caso em uma metalúrgica

necessárias, mas que não agregam valor ao processo, e apenas $4 \%$ corresponde aos desperdícios.

Figura 9 - Yamazumi dos processos propostos.

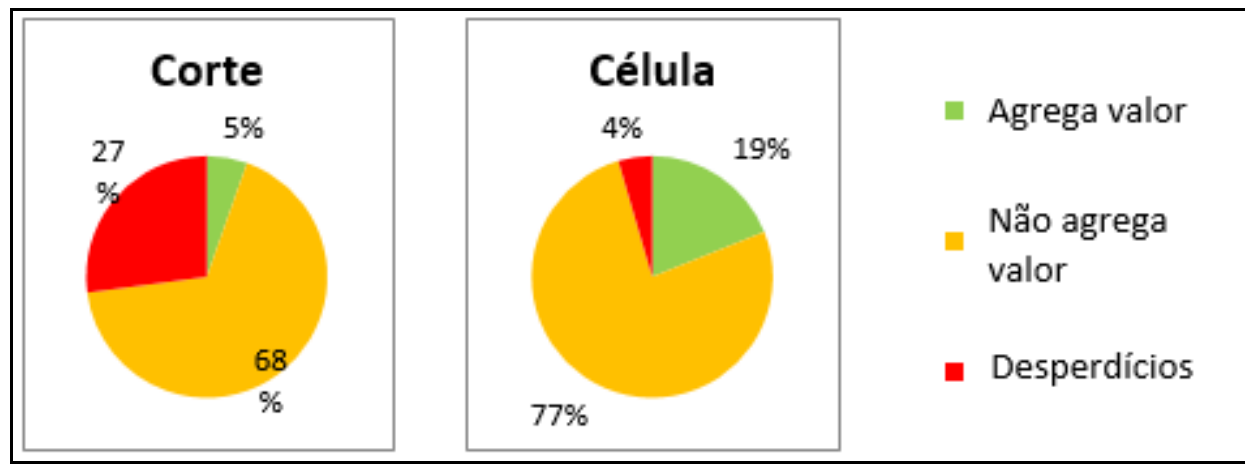

Fonte: Os autores (2018).

Quanto a ordem de produção do processo futuro para a fabricação do terminal K, esta seria constituída por 4 processos, sendo o primeiro processo o corte, o segundo processo a célula de manufatura, o terceiro consiste na zincagem e a quarta operação corresponde a limpeza interna e armazenamento, ambos no mesmo processo.

Deve-se levar em consideração que os tempos de processo podem apresentar pequenas variações, uma vez que o trabalho é realizado por trabalhadores que podem apresentar diferentes desempenhos uns dos outros, o que por sua vez, não impactaria de forma considerável nos resultados.

\section{DISCUSSÕES}

\subsection{Redução no tempo de produção e giro de estoque}

Conforme o mapeamento do fluxo de valor atual e proposto, o tempo total de fabricação seria reduzido em 8 dias. Com essa melhoria, a empresa teria um ganho potencial no tempo de produção de 27,58\%, podendo ser produzidas 3 peças a mais por dia, considerando que a saída mensal em média é de 227 peças. Com a melhoria, o coeficiente de giro de estoque seria de 1,28 kg/dia. Esse ganho potencial foi de 37,63\%, significando ganhos em tempo de estoque de produto acabado, gerando um melhor fluxo de produção e valor financeiro. 
Proposta de implantação de uma célula de manufatura: um estudo de caso em uma metalúrgica

\subsection{Redução no número de colaboradores}

No estado atual, ponderando apenas os processos unificados na célula de manufatura, fazem-se necessários 06 funcionários, um para cada processo. Já no processo proposto, esse número ficaria em 3 pessoas para operar as 6 máquinas devido ao layout celular em formato de $\mathrm{U}$, possibilitando que o operador seja multifuncional. $\mathrm{O}$ trabalho das 03 pessoas restantes pode ser recolocado em outras funções.

\subsection{Fechamento da ordem de produção}

$\mathrm{Na}$ operação do fechamento da ordem de produção do processo atual, considerando somente os 6 processos agrupados, são necessários 294 segundos para o fechamento dos 6 códigos de barra. Já na ordem de produção do processo futuro, seria gerado apenas um código de barras, resultado em 50 segundos. Isso consiste em uma redução de $488 \%$, o que é um valor significativo, considerando a alta demanda por esses itens.

\subsection{Minimização da distância percorrida}

De acordo com o acompanhamento de uma ordem de produção na fábrica, o tempo usado com a movimentação de peças de um processo até o outro no processo atual, para a fabricação de um lote do terminal K, é de 324 segundos. Já o tempo necessário para movimentação no processo proposto é de 178 segundos, mostrando uma redução significativa considerando uma grande quantidade de produção de diferentes lotes diários. Quanto à distância percorrida com movimentação de material, enquanto no processo atual o percurso é de 162 metros, no processo proposto esta distância corresponde a 89 metros, sendo visível a minimização do deslocamento do operador.

\subsection{Redução do tempo de setup}

Outro benefício relacionado a redução de tempo está no tempo de setup total dos processos, onde no processo atual para a fabricação de um lote do terminal K este tempo é de 2601 segundos, enquanto no processo proposto é de 1107 segundos, apresentando redução de $57 \%$.

\subsection{Otimização do estoque entre processos e estoque de material}


Proposta de implantação de uma célula de manufatura: um estudo de caso em uma metalúrgica

$\mathrm{Na}$ célula de manufatura, a quantidade de estoques de material entre processos seria reduzida, uma vez que a matéria prima se desloca dentro da célula continuamente, não haveria material aguardando processo. Por se tratar de uma célula com layout por produto em forma de U, a área se torna restrita, o que reduz o estoque intermediário, sincronizando a produção conforme a demanda.

\subsection{Redução de desperdícios}

Comparando dados do Yamazumi, através da Figura 10 é possível analisar a classificação das atividades do processo atual e proposto, onde afirma-se a notável otimização dos processos.

Figura 10 - Classificação do processo atual e proposto.

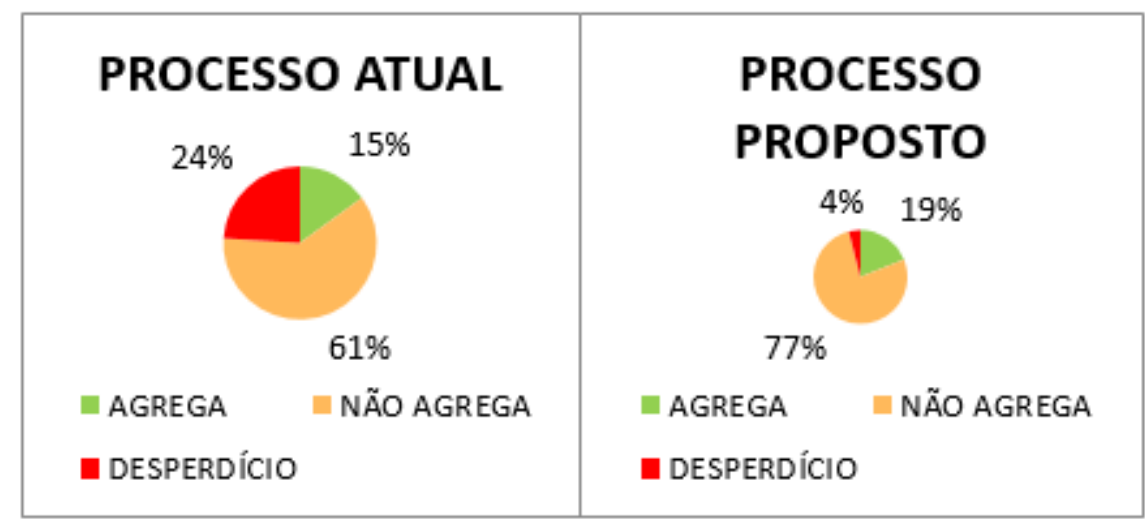

Fonte: Os autores (2018).

As atividades de agregação de valor foram de $15 \%$ foi para $19 \%$ o que significa que assim a capacidade produtiva da fábrica estaria sendo melhor explorada. De modo geral, o estudo apresentou a diminuição dos desperdícios em $20 \%$.

\section{CONCLUSÕES}

Com o propósito de permanecerem competitivas, as empresas estão em contínua busca pelo aprimoramento de seus sistemas produtivos, uma vez que metodologias sólidas e bem estruturadas relacionadas aos processos são imprescindíveis na concretização de tais objetivos. Para tanto, é preciso conhecer a empresa, trabalhando para que haja o 
Proposta de implantação de uma célula de manufatura: um estudo de caso em uma metalúrgica

balanceamento entre capacidade produtiva e demanda, conhecendo suas necessidades e seus pontos fracos e atacando nestes.

O presente trabalho apresentou à empresa laboratório para o estudo, uma série de melhorias a partir do estudo, por isso atendeu ao objetivo de propor a implantação de uma célula de terminais de mangueira de ar condicionado em uma empresa do ramo metal mecânico que atenda às suas necessidades de aumento produtivo e eliminação de desperdícios.

Apresentou-se a proposta da célula de manufatura, em que seis processos seriam agrupados em um layout celular em forma de U, posteriormente desenvolveu-se o mapa de fluxo de valor futuro, onde foi possível observar a redução de 8 dias no tempo total de produção, além do ganho potencial de 37,63\% com giro de estoque, redução de 3 pessoas no processo do item estudado, redução no tempo de fechamento da ordem de produção, bem como a diminuição do tempo de setup e distância percorrida.

Não foi considerada a questão dos custos relacionados à implementação de uma célula de manufatura na empresa laboratório do estudo. Como sugestões de trabalhos futuros relacionados a este caso, salienta-se o estudo de payback, com o fim de saber o prazo de recuperação do capital investido com a célula de manufatura proposta, visto que este não foi o objetivo da pesquisa em questão.

Por fim, ressalta-se a importância da Engenharia de Produção no âmbito organizacional, onde é imprescindível o uso de técnicas e ferramentas visando a melhoria contínua dos sistemas produtivos, envolvendo processos, pessoas, materiais e máquinas, buscando sempre o aperfeiçoamento de técnicas para alcançar os objetivos almejados.

\section{Referências}

BARTZ, A. P. B.; WEISE, A. D.; RUPPENTHAL, J. E. Aplicação da manufatura enxuta em uma indústria de equipamentos agrícolas. Ingeniare. Revista chilena de ingeniería, v. 21 , n. 1, p. 147-158, 2013.

BLACK, J. T. O projeto da fábrica com futuro. Porto Alegre: Bookman, 1998.

CONCEIÇÃO, S. V. Otimização do fluxo de materiais através da manufatura celular. Production, v. 15, n. 2, p. 235-250, 2005.

GADELHA, F. C. et al. Alteração de um layout funcional para layout celular motivado pelos fundamentos da manufatura enxuta: estudo de caso em indústria de transformadores. HOLOS, v. 6, p. 156-169, 2015. 
Proposta de implantação de uma célula de manufatura: um estudo de caso em uma metalúrgica

KOENIGSAECKER, G. Liderando a Transformação Lean nas Empresas. Porto Alegre: Bookman, 2011.

LEITE, J. V. G. A. et al. Melhoria de Processo Operacional Utilizando Mapa de Fluxo de Valor em Uma Indústria Metal Mecânica. Revista FSA, v. 14, n. 5, p. 146-170, 2017.

MARTINS, P. G.; LAUGENI, F. P. Administração da produção fácil. São Paulo: Saraiva, 2012.

NAWANIR, G.; LIM, K. T.; OTHMAN, S. N. Lean manufacturing practices in Indonesian manufacturing firms. International Journal of Lean Six Sigma, v. 7, n. 2, p. 149-170, 2016.

PEINADO, J.; G., ALEXANDRE R. Administração da Produção (Operações Industriais e de Serviços). Curitiba: UnicenP, 2007. Disponível em: https://www.google.com/url?sa=t\&rct=j\&q=\&esrc=s\&source=web\&cd=1\&ved=2ahUKEwio oJS0ie_jAhULK7kGHY9hDpwQFjAAegQIAhAC\&url=http\%3A\%2F\%2Fpaginapessoal.utfp r.edu.br $\% 2$ Fjurandirpeinado $\% 2$ Flivro-administracao-da-producao $\% 2$ Flivro-administracao-daproducao\%2Flivro2folhas.pdf\%2Fat_download\%2Ffile\&usg=AOvVaw1v8Pjt7Ir829ZI_6kze xET. Acesso em 10 jan 2018.

PIEŃKOWSKI, M. Waste measurement techniques for lean companies. Lean Thinking, v. 5, n. 1, p. 1-16, 2014.

PINHEIRO, L. M. P.; TOLEDO, J. C. Aplicação da abordagem lean no processo de desenvolvimento de produto: um survey em empresas industriais brasileiras. Gestão \& Produção, v. 23, n. 2, p. 320-332, 2016.

PRATES, C. C.; BANDEIRA, D. L. Aumento de eficiência por meio do mapeamento do fluxo de produção e aplicação do Índice de Rendimento Operacional Global no processo produtivo de uma empresa de componentes eletrônicos. Gestão \& Produção, v. 18, n. 4, p. 705-718, 2011.

ROSA, G. P. et al. A reorganização do layout como estratégia de otimização da produção. GEPROS. Gestão da Produção, Operações e Sistemas, v. 9, n. 2, p. 139-154, 2014.

ROTHER, M.; HARRIS, R. Criando Fluxo Contínuo: Um Guia de Ação para Gerentes, Engenheiros e Associados da Produção. São Paulo: Lean Institute Brasil, 2008.

ROTHER, M.; SHOOK, J. Aprendendo a Enxergar: Mapeando o Fluxo de Valor para Agregar Valor e Eliminar o Desperdício. São Paulo: Lean Institute Brasil, 2012.

SANTOS, L. A. et al. Layout celular: proposta e implantação em empresa start-up de tecnologia. Revista GEINTEC, v. 6, n. 4, p.3447-3460, 2016.

SHINGO, S. O Sistema Toyota de Produção. 2. ed. Porto Alegre: Bookman, 1996.

TRINTIN, J. R. A.; SELLITTO, M. A. Método para formação de células de fabricação: aplicação em uma empresa da indústria metal-mecânica. Revista Liberato, v. 14, n. 21, p. 6176, 2013.

WOMACK, J. P.; JONES, D. T. Enxergando o Todo: mapeando o fluxo de valor estendido. São Paulo: Lean Institute Brasil, 2011.

A mentalidade enxuta nas empresas: elimine o desperdício e crie riqueza. Rio de Janeiro: Elsevier, 2004. 
Proposta de implantação de uma célula de manufatura: um estudo de caso em uma metalúrgica

YIN, R. Estudo de Caso: planejamento e método. Porto Alegre: Bookman, 2001. 